\title{
Real-time Study of Mechanism of 3D Pore-Widening for Nano-Porous Anodic Alumina Based on a Multilayer Structure Theory
}

\author{
Ba Hanqing ${ }^{1}, \quad$ Wang Kaige ${ }^{1}, \quad$ Jiao Yang ${ }^{1}, \quad$ Jin Aizi ${ }^{2}, \quad$ Bai Jintao', ${ }^{1} \quad$ Gu Changzhi ${ }^{2}$ \\ ${ }^{1}$ State Key Laboratory of Cultivation Base for Photoelectric Technology and Functional Materials, Laboratory of Optoelectric Technology of \\ Shaanxi Province, National Center for International Joint Research of Photoelectric Technology \& Nano-functional Materials and Application, \\ Northwest University, Xi'an 710069, China; ${ }^{2}$ Institute of Physics, Chinese Academy of Sciences, Beijing 100190, China
}

\begin{abstract}
The uniformity of the pore size and the morphology of nano-porous anodic alumina (nano-PAA) can be improved by a pore-widening process. The evolution of the pore diameter and the morphology was investigated in real time. Phosphoric acid solution ( $3 \mathrm{wt} \%)$ was used as the etchant to chemically enlarge the pores of a nano-PAA prepared with oxalic acid. It is found that the pore-widening is carrying out simultaneously both on top-view and cross-section. From the top-view analysis, the pore diameter gradually enlarges with the increasing of etching time. However, such enlarging rate varies with the multilayer structure of the pore wall. From the cross-section analysis, the pores walls of a multilayered amorphous compound are etched in a stage-by-stage mode until almost everything is etched away. The pore-widening procedure on the upper portion is completed earlier respect to the lower portion, after some time the pore-widening becomes uniform along the axial direction. If the etching is maintained, hexagonal pore walls will be destroyed and split into ultrahigh aspect ratio nanowires due to the etching anisotropy, and finally completely dissolved. Combining analyses in the depth direction with stereoscopic 3D imaging the results clarify the pore-widening mechanism in 3D nano-PAA.
\end{abstract}

Key words: nano-porous anodic alumina; mechanism of pore-widening; multilayer structure; cross-section

Nano-porous anodic alumina (nano-PAA) has been attracting attention due to the wide applications in various industrial fields such as aeronautics, architectural decoration or anti-corrosion protection ${ }^{[1-3]}$. Recently, a new round of research enthusiasm on this material has been promoted by advances in 3D nanoscience and nanotechnology. Based on nano-PAA, various kinds of nanoscale functional structures, e.g., OD nanodots, 1D nanowires, 2D nanochannels and 3D taper-pore arrays, have been fabricated with different materials such as $\mathrm{Au}, \mathrm{Ag}, \mathrm{Ni}, \mathrm{Cu}$ and $\mathrm{Pd}-\mathrm{Ni}$ etc. ${ }^{[4-8]}$. The rapidly increasing interest in nanoscale materials has propelled the nano-PAA to the fore as one of the most popular nanomaterials with application across a gamut of areas in- cluding molecular separation, catalysis, energy generation and storage, electronics and photonics, sensors, and drug delivery ${ }^{[9-13]}$.

The development of practical applications has resulted in more and more stringent requirements on the control of nano-PAA morphological features. Nano-PAA with a uniform morphology can be fabricated by the two-step anodic oxidation method ${ }^{[14]}$. The pore-widening is within the most effective processes for preparing nano-PAA with a high-controlled morphology. The essence of the pore-widening process relies on the chemical etching of amorphous oxide pore walls by acid or alkaline reagents, to enlarge the interior space of nano-holes in three-dimensional (3D) process. ${ }^{[15]}$

Received date: January 03, 2017

Foundation item: National Natural Science Foundation of China (61378083); International Cooperation Foundation of the National Science and Technology Major Project of the Ministry of Science and Technology of China (2011DFA12220); Major Research Plan of National Natural Science Foundation of China (91123030); Natural Science Foundation of Shaanxi Province of China (14JS106)

Corresponding author: Wang Kaige, Ph. D., Researcher, Institute of Photonics and Photon Technology, Northwest University, Xi'an 710069, Tel: 0086-29-88303687, E-mail: wangkg@nwu.edu.cn

Copyright $@ 2017$, Northwest Institute for Nonferrous Metal Research. Published by Elsevier BV. All rights reserved. 
Pore-widening has been experimentally studied; Hu et al. reported that a proper morphology of nano-PAA could be achieved with the etching solution of $3 \mathrm{wt} \% \mathrm{H}_{3} \mathrm{PO}_{4}{ }^{[16]}$. Nagaura et al. fabricated nano-PAA with various inverted cone holes by employing the alternate repetition of anodization and pore-widening processes. In addition, based on this kind of template, they were able to prepare a regular arrangement of nanoparticle arrays, such as conical nickel and gold ${ }^{[17]}$. However, to the best of our knowledge, the 3D mechanism of pore-widening and the nanopores evolution have been seldom reported in details. To precisely control the shape and size of nano-PAA in microscopic dimensions, one essential prerequisite is to clarify the microscopic mechanism of pore-widening. For this, further investigations showing nanopores dynamic evolution in $3 \mathrm{D}$ are required.

In this paper, the $3 \mathrm{D}$ pore-widening process of nano-PAA was performed by chemical etching with a $3 \mathrm{wt} \% \mathrm{H}_{3} \mathrm{PO}_{4}$ at $20{ }^{\circ} \mathrm{C}$. The real-time evolution of pore diameter and shape from both the top-view and cross-section have been studied to reveal the mechanism of pore-widening of nano-PAA with multilayer structure.

\section{Experiment}

A super-high purity (99.999\%) aluminum (Al) sheet was cut into small $15 \mathrm{~mm} \times 15 \mathrm{~mm}$ pieces, annealed in a vacuum tube furnace at $600{ }^{\circ} \mathrm{C}$ for $5 \mathrm{~h}$ (Nitrogen as protective gas) and ultrasonically cleaned to remove surface impurities with acetone, ethanol and deionized water for $10 \mathrm{~min}$. Samples were then put into a $5 \mathrm{wt} \% \mathrm{NaOH}$ solution for 15 min to completely eliminate the surface oxide layer. Cleaned samples were then electrochemically polished under the voltage of $3 \mathrm{~V}$ at $75^{\circ} \mathrm{C}$ for $15 \mathrm{~min}$ in an electrolyte including chromic acid, sulfuric acid and phosphoric acid in the proportion of $2: 5: 20$.

After that, the standard two-steps anodic oxidation method was employed to fabricate nano-PAA from the cleaned Al sheet. During the first anodization step, the Al sheet was anodized in a $0.3 \mathrm{~mol} / \mathrm{L}$ oxalic acid solution at 40 $\mathrm{V}$ at $0{ }^{\circ} \mathrm{C}$ for $2 \mathrm{~h}$ and then the top surface of nano-PAA was removed by immersing the sheet into a mixture solution containing $0.6 \mathrm{~mol} / \mathrm{L}$ phosphoric acid and $0.15 \mathrm{~mol} / \mathrm{L}$ chromatic acid. The second oxidation step was then accomplished under the same working condition as that of the first anodizing step.

The pore-widening etching was performed for prepared nano-PAA by a $3 \mathrm{wt} \%$ phosphoric acid $\left(\mathrm{H}_{3} \mathrm{PO}_{4}\right)$ solution at $20{ }^{\circ} \mathrm{C}$ for various periods, i.e. $30,40,50,60,70,80,90$, $100,110,120$, and $130 \mathrm{~min}$. The $3 \mathrm{wt} \%$ concentration of $\mathrm{H}_{3} \mathrm{PO}_{4}$ was chosen in order to maintain the nano-PAA morphology during the pore-widening process. At this concentration value, the slow etching rate allowed for a precise control of the pore modifications of the nano-PAA.
Field emission scanning electron microscopy (FE-SEM, SU8010) was used to characterize the surface and cross-section morphology of the etched nano-PAA. The elemental composition and type of nano-PAA were determined by energy dispersive X-ray Spectrometry (EDS, JEM-2100,) and X-ray diffraction (XRD-7000). Transmission electron microscopy（TEM, FEI Tecnai G2 F20) was used to study the crystal lattice structure of pore walls.

\section{Results and Discussion}

\subsection{Pore-widening from the top-view}

The nano-PAA pore morphology evolution at different etching stages are displayed in top-view FE-SEM images in Fig.1. Various pore-widening time of 0, 30, 40, 50, 60, 70, $80,90,100,110,120$, and $130 \mathrm{~min}$ are reported. From Fig.1a, it is found that the morphology in the pristine nano-PAA is irregular as elliptic or approximately circular, and pore diameters are non-uniform. Moreover, cell borders (skeleton) of nano-PAA are not perfectly hexagonal, the arrangement is disordered and the average pore diameter is about $20 \mathrm{~nm}$.

After the pore-widening process, it can be obviously seen that the pore diameter increases with the etching time and finally tends to be consistent. Simultaneously, the spacing between pores decreases and ultimately becomes constant.

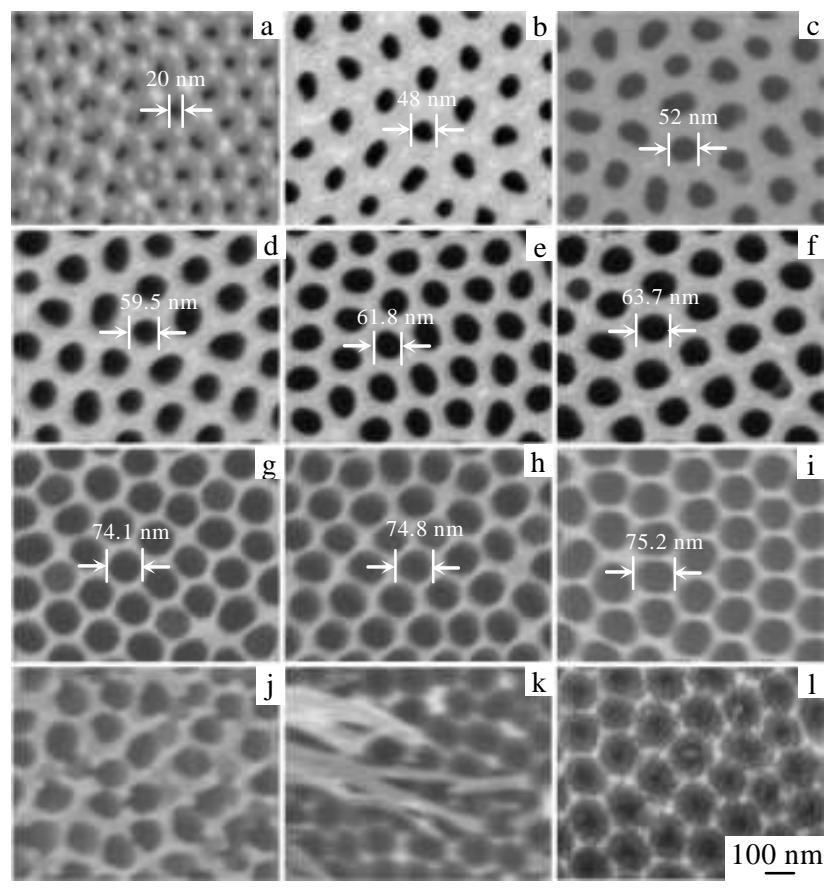

Fig.1 FE-SEM top-surface morphologies of pores at various etching stages: (a) initial state, (b) after pore-widening 30 min, (c) $40 \mathrm{~min}$, (d) $50 \mathrm{~min}$, (e) $60 \mathrm{~min}$, (f) $70 \mathrm{~min}$, (g) 80 min, (h) $90 \mathrm{~min}$, (i) $100 \mathrm{~min}$, (j) $110 \mathrm{~min}$, (k) $120 \mathrm{~min}$ and (1) $130 \mathrm{~min}$ 
Meanwhile, the morphology of nano-PAA becomes more uniform, i.e. with a more regular pore shape. In particular, it can be found that the morphology of some pores (Fig.1i) has become approximately hexagonal, which indicate that the internal amorphous oxides have been etched off completely. It should be noticed that the pore density of the nano-PAA, calculated to be $1.2 \times 10^{10}$ pore $/ \mathrm{cm}^{2}$, does not change after the pore-widening treatment. This result is in agreement with a previous one ${ }^{[16]}$.

Fig.1j shows that the hexagonal cell structure is destroyed after the etching time of $110 \mathrm{~min}$, which results in the generation of nanowires with various shapes. Since the aspect ratio of nanowires is too large to sustain the complete structure, nanowires collapse when the pore-widening time exceeds $110 \mathrm{~min}$. These nanowires correspond to the juncture section between three neighboring pores. When the pore-widening time exceeds $130 \mathrm{~min}$, the only thing which remains is nano-concave objects lying at the bottom, as nanowires were fully dissolved by the $\mathrm{H}_{3} \mathrm{PO}_{4}$ solution, as shown in Fig.11.

We investigated the nanowires composition and structure by energy dispersive X-ray spectrometry (EDS) (Fig.2a) and X-ray diffraction (XRD) (Fig.2b). It can be seen that the only $\mathrm{O}$ and $\mathrm{Al}$ elements are present in the nanowire, and the ratio between the two elements is not the theoretical 3:2; which is ascribed to the effect of the Al substrate. The $\mathrm{X}$-ray diffraction pattern of the nano-PAA, and the Al substrate are taken in order to examine the crystal structure of the nanowires.

As shown in Fig.2b, the XRD pattern of the nanowire shows a wide $2 \theta$ range of envelop in $20^{\circ} \sim 40^{\circ}$, which indicates the diffraction peak of $\mathrm{Al}_{2} \mathrm{O}_{3}$. The (200) peak located at $44.7^{\circ}$ and the (311) peak at $77.2^{\circ}$ are clearly distinguishable and can be indexed to the Al substrate as compared with the standard JCPDS card (4-783).

In order to analyze the mechanism of the pore-widening process from the top-view, we extracted the pore diameter as a function of the pore-widening time, as shown in Fig.3. It can be clearly observed that the pore-widening process can be divided into three stages. At the first stage, corresponding to an etching time lower than $40 \mathrm{~min}$, the pore diameter increases slowly with the error of $3 \mathrm{~nm}$. At the second stage, between 40 and $50 \mathrm{~min}$, the pore diameter increases significantly with the etching time. At the third stage, between 50 and $100 \mathrm{~min}$, the pore diameter increases similarly to the first stage. The inset in Fig.3 shows the average chemical etching rate as a function of time. The etching rate is about $0.14 \mathrm{~nm} / \mathrm{min}$ and $0.18 \mathrm{~nm} / \mathrm{min}$ during the first and the third stage, respectively while it is about $0.9 \mathrm{~nm} / \mathrm{min}$ during the second stage.

During the pore-widening process, the working conditions such as the temperature and the concentration of phosphoric acid were not varied. It is reasonable then to
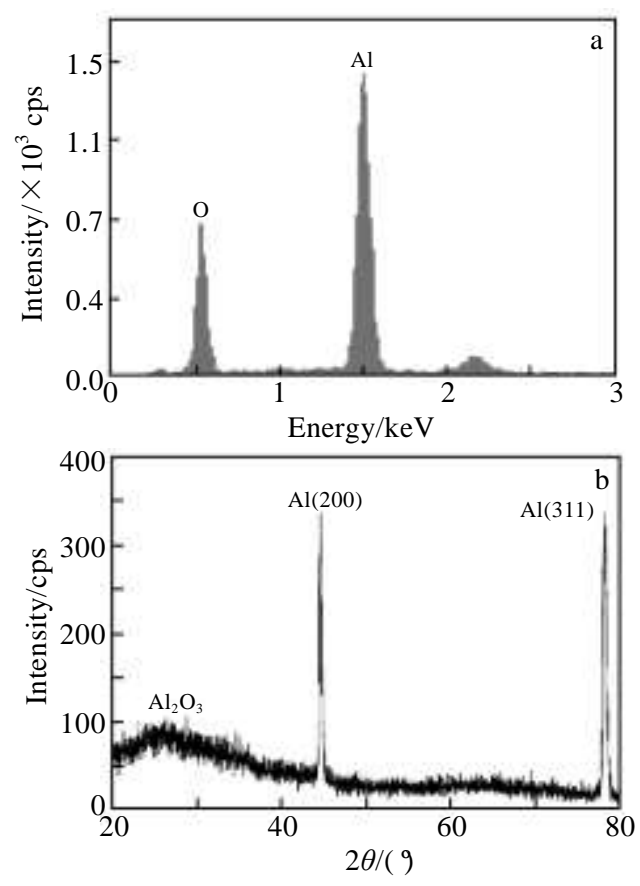

Fig.2 EDS (a) and XRD (b) characterizations of a nanowire resulting from the etching of nano-PAA

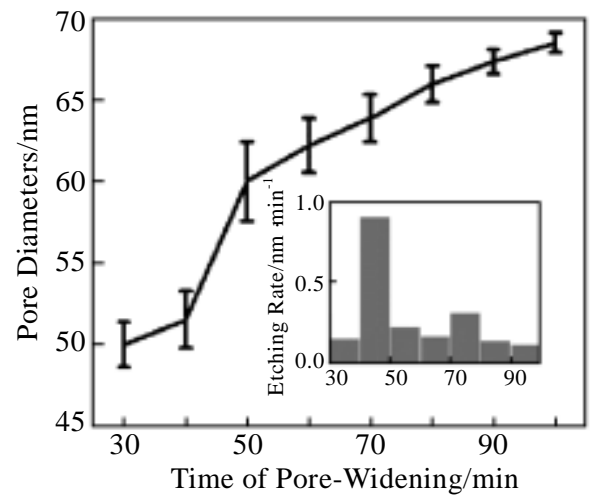

Fig.3 Pore diameter as a function of the pore-widening time (the inset shows the relationship between the etching rate and the etching time)

assume that the aforementioned three stages of pore-widening can be ascribed to the multilayer structure of pore wall of anodic aluminum oxide, which means that the pore-widening procedure should be closely related with the chemical composition of pore walls.

Fig.4a schematically shows a diagram of the nano-PAA multilayer structure, indicating that cells are composed of a skeleton layer with high crystallinity and multiple additional amorphous layers, which are all around the pore center. Farnan et $\mathrm{al}^{[18]}$. have further recognized and clarified that anodic alumina walls are amorphous and include a variable mixtures of aluminum oxide, compounds and water 


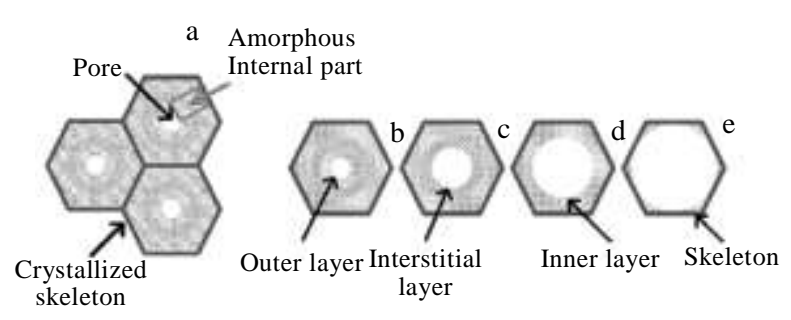

Fig.4 Diagram of top-view of pore-widening process in its different stages

molecules. Although the pore wall has an amorphous structure, there are fine differences among layers. Therefore, during the pore-widening process, there are different stages as displayed in Fig.4. Compared with the pure alumina of the cell skeleton (pore borders), the pore walls made of contaminated alumina are dissolved relatively more easily by the solution, which results in a rapid enlargement of the pore size ${ }^{[19]}$. The chemical dissolution of the skeleton is slower, which is attributed to absence of impurities, such as $\mathrm{C}_{2} \mathrm{O}_{4}{ }^{2-}$ anions ${ }^{[20]}$.

According to this, Fig.4b 4e schematically shows the evolution of the multilayer structure of the nano-PAA during the pore-widening process. Fig. $4 \mathrm{~b}$ describes the nano-PAA surface morphology without pore-widening. The pore wall can be divided into three layers (according to Fig.3), with the skeleton being the outside shell. Maybe, the pore wall can be divided into more layers, but this would need further investigations in the future. With the pore-widening, the outer layer is chemically etched out and then the process starts on the second layer, as shown in Fig.4c. Fig.4d describes the situation of the pore wall with the remaining inner layer closest to the skeleton. When the pore-widening process ends, the amorphous pore walls are etched away so that only the crystallized skeleton is left, as shown in Fig.4e.

At the end, the skeleton part will eventually be corroded into nanowires, which will collapse owing to their ultrahigh aspect ratio, which cannot support their standing. This development process corresponds to the images displayed in Fig. $1 \mathrm{j}-1 \mathrm{k}$.

\subsection{Pore-widening from the cross-section analysis}

In order to accurately characterize the structural evolution of the nano-PAA along the axial direction during the pore-widening process, the morphologies and diameters of pores have been monitored. Fig. 5 shows FE-SEM images of the cross-section morphologies during the pore-widening; experiments were carried out from $0 \mathrm{~min}$ to $100 \mathrm{~min}$ etching time. Fig.5a shows the SEM image of the pore cross-section without pore-widening; the pore diameters at different positions, e.g., the upper $a_{1}$, the middle $a_{2}$ and the lower $\mathrm{a}_{3}$, have a similar size of about $19.8 \mathrm{~nm}$. The array structure with smaller pore diameter are not suitable for most practical applications, such as to be employed as template for the fabrication of nano-antenna arrays ${ }^{[21]}$ or SERS substrates $^{[22]}$. In this case it is needed to widen the pore size and modulate the morphology of nano-PAA. Moreover, it is necessary to explore the enlarging process and cross-section morphology along the axial direction in great details.

Fig.5b shows the cross section morphologies of nano-PAA after $30 \mathrm{~min}$ of pore-widening; the pore diameter on the upper part $\left(b_{1}\right)$, the middle part $\left(b_{2}\right)$ and the lower part $\left(b_{3}\right)$ display different values of $48.7,35.7$ and $27.8 \mathrm{~nm}$, respectively. It can be seen that after $30 \mathrm{~min}$ of pore-widening, the channel diameter is obviously enlarged. However, along the axial direction, the diameter of the upper part results to be larger respect to the lower part. The diameter magnification in the upper, middle and lower channel, defined as $\left(\left(b_{i}-a_{i}\right) / a_{i}\right)$ is about $1.46,0.80$ and 0.40 , respectively. In other words, the pore-widening rate is not constant along the axial direction and gradually decreases from the top to the bottom. So far, this is the first experimental report on the structural evolution details of alumina nano-pores along the depth direction, and in the stereoscopic 3D view.

Fig.5c shows the cross-section morphology of nano-PAA channels after $60 \mathrm{~min}$ of etching; the diameters on the upper, middle and lower parts are 65.5, 58.6 and $51.7 \mathrm{~nm}$, respectively. The magnification $\left(\left(\mathrm{c}_{i}-\mathrm{b}_{i}\right) / \mathrm{b}_{i}\right)$ of the diameter of the upper, middle and lower channel are 0.34, 0.64 and 0.86 , respectively. By comparing with the results obtained during the first $30 \mathrm{~min}$ of etching (Fig.5b), it means that the pore-widening rate is in a reversal order during the 30 60 min period. So the pore-enlarging rate in the lower part results to be faster than the one in the upper channel portion.

By continuously etching the nano-PAA, after $100 \mathrm{~min}$ the morphology is as shown in Fig.5d; pore diameters in the upper, middle and lower part have converged to the same value of $75.1 \mathrm{~nm}$. The magnification $\left(\left(\mathrm{d}_{i}-\mathrm{c}_{i}\right) / \mathrm{c}_{i}\right)$ of the diameter of the upper, middle and lower part of channel is $0.09,0.22$ and 0.38 , respectively. So, by comparing the 100 min morphology with the $60 \mathrm{~min}$ one (Fig.5c), the pore-widening rate in the lower part region results to be higher than the one in the upper part region.

Fig. 6 shows electron diffraction patterns for different pore wall structures obtained from the internal part (a), the skeleton of the nano-PAA (b) and the skeleton after $30 \mathrm{~s}$ of electron beam exposure (c), which are used to highlight the crystallization of the different parts. The internal part and the skeleton are initially both amorphous. This amorphous state persist in the case of the internal part after $30 \mathrm{~s}$ of electron beam exposure, while the skeleton becomes crystallized. 


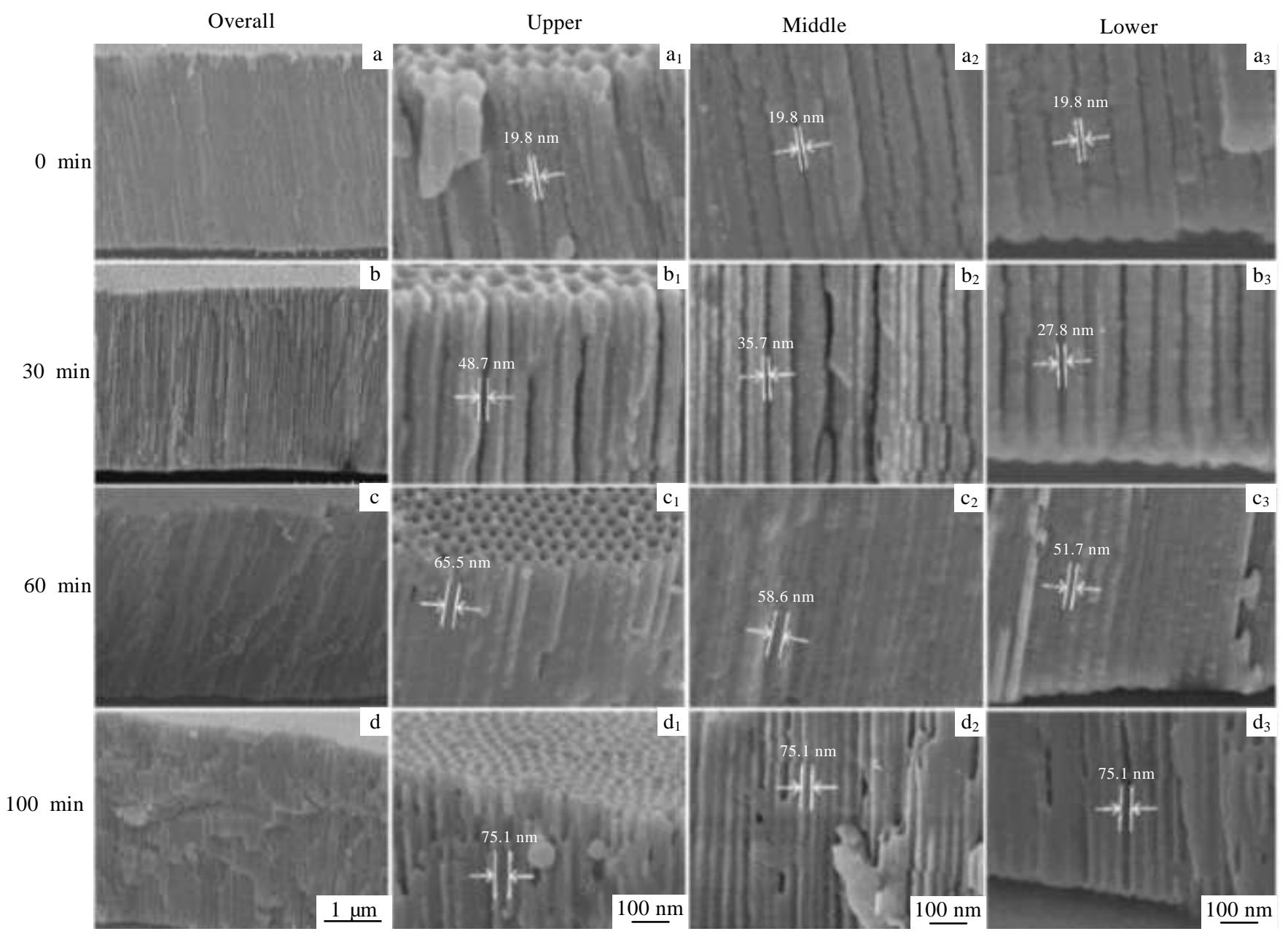

Fig.5 Cross-sectional morphologies of the nano-PAA after various time of pore-widening
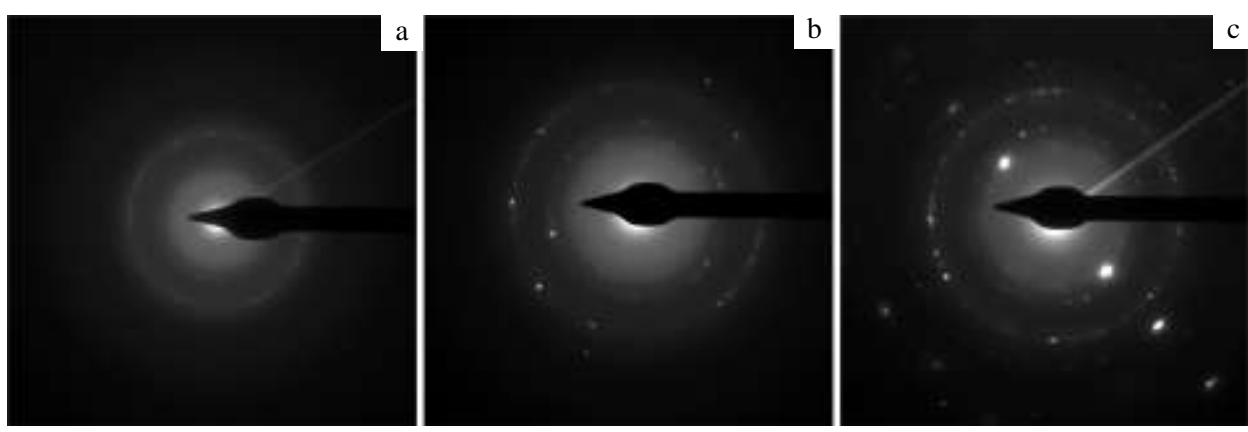

Fig.6 Electron diffraction patterns for different pore wall structures, obtained from the internal part (a), the skeleton of the nano-PAA (b) and the skeleton after $30 \mathrm{~s}$ of exposure to the electron beam (c)

To better explain the differences in the trends on each etching period, the magnification $(\Delta R / R)$ at different locations along the axial (depth) direction are displayed in Fig.7. It can be concluded that during the earlier 30 min of etching, the effect of pore-widening in the upper portion is more efficient, meaning that the innermost amorphous wall in the upper part has been chemical etched away earlier. However, during the following pore-widening time, after $30 \mathrm{~min}$, the etch rate in the middle and lower parts are higher than in the upper part, so that the difference between the pore diameter among these three kinds of locations becomes smaller.

Fig. 8 summarizes results from both the top-view and the cross-section analyses; the pore-widening mechanism and the 3D morphology changes of nano-PAA have been characterized in details by observing the morphology in the ini- 


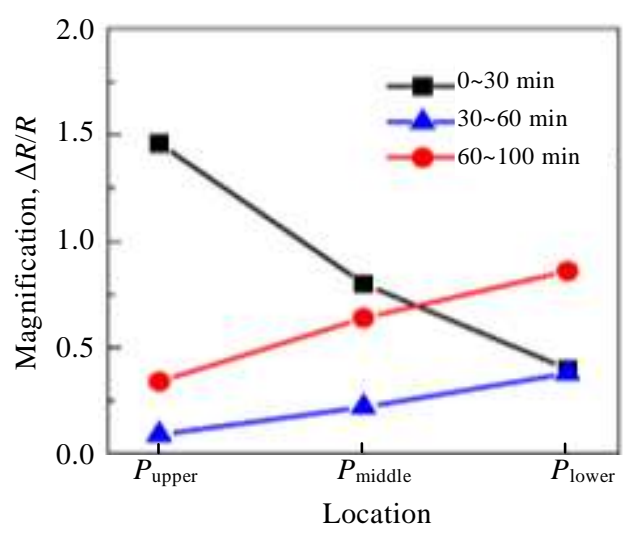

Fig.7 Relative pore-widening rate at different locations (upper, middle and lower) along the axial direction

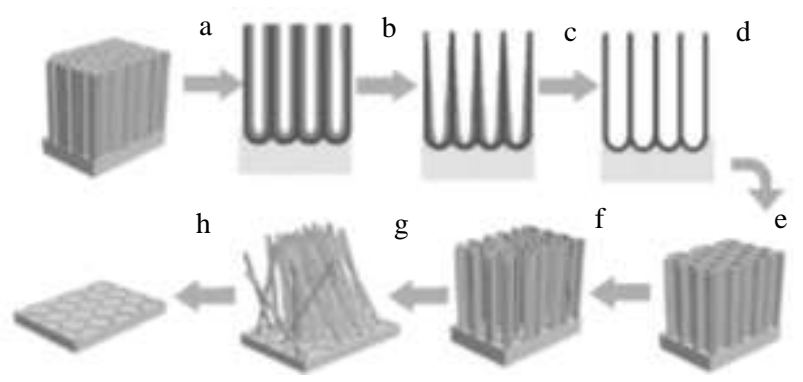

Fig.8 Schematic diagram of the pore-widening mechanism in nano-PAA

tial state, i.e. before the pore-widening, showing a small pore size and relatively non-uniform size distribution (Fig.8a). Then, after the etching process, the pore structure will be adjusted in both surface and cross-section at the same time (Fig.8b 8d). During chemical etching of the first layer, since the convection and interchange of chemical reagents in the lower section are weaker than that in the upper part, the etching rate in the lower part is smaller. Thus the pore-widening process at the upper part is completed earlier than in the lower section. However, the chemical etch rate is not constant as it varies with the composition of the alumina layer. For a long etch time, the pore-widening rate of the upper section gradually declines, while in the lower part it increases. Finally, the morphology of nano-PAA becomes homogeneous and the diameters of pores/holes become consistent (Fig.8e). When the pore-widening time further increases, the amorphous part inside the skeleton of the unit cell is chemically etched off. As the chemical reaction keeps going, the skeleton structure is destroyed. The skeleton cracks in the thinnest wall between two neighboring pores and the hexagonal pore structure is destroyed (Fig.8f). Since the juncture between three neighboring pores is the thickest portion, the pore walls will be split from the upper till the lower portion, producing a variety of nanowires. These nanowires will finally easily collapse since they have a relative large aspect ratio (Fig.8g). Finally, the bowl-like structure of the nano-PAA substrate will be exposed out when the nanowires are rinsed off completely (Fig.8h).

\section{Conclusions}

1) From the top-view analysis, the pore diameter results to be enlarged from the initial size of $\sim 20 \mathrm{~nm}$ to the finial diameter of $\sim 75 \mathrm{~nm}$. Moreover, a pore-widening rate of $0.14,0.9$ and $0.18 \mathrm{~nm} / \mathrm{min}$ are found, corresponding to the etching of three layers of different composition going from the center pore to the skeleton part.

2) Meanwhile, from the cross-section analysis, the pore-widening at the upper part is earlier completed than the lower part in the initial etching time, and gradually become uniform with pore diameter of $75 \mathrm{~nm}$ after about 100 min of pore-widening.

3 ) If the etching continues, hexagonal pore walls are destroyed and split into nanowires, which then dissolve completely.

\section{References}

1 Dudem B, Leem J W, Lim J H et al. Rsc Advances[J], 2015, 5(109): 90103

2 Zhao Y, Cong W, Yang L et al. Nanoscale Research Letters[J], 2014, 10(1): 1

3 Xiao Z L, Han C Y, Welp U et al. Applied Physics Letters[J], 2002, 81(15): 2869

4 Yang Q, Sha J, Xu J et al. Chemical Physics Letters[J], 2003, 379(1): 87

5 Wang Z, Su Y K, Li H L. Applied Physics A[J], 2002, 74(4): 563

6 Sauer G, Brehm G, Schneider S et al. Journal of Applied Physics[J], 2002, 91(5): 3243

7 Liu X, He J, Zhou J et al. Rare Metal Materials \& Engineering [J], 2007, 36(12): 2228 (in Chinese)

8 Wang J, Yue E, Yu G et al. Rare Metal Materials and Engineering $[\mathrm{J}], 2007,36(1): 126$ (in Chinese)

9 Takmakov P, Vlassiouk I, Smirnov S. Analytical \& Bioanalytical Chemistry[J], 2006, 385(5): 954

10 Buijnsters J G, Rui Z, Tsyntsaru N et al. Acs Applied Materials \& Interfaces $[\mathrm{J}], 2013,5(5): 3224$

11 Fang Z, Wang Y, Peng X et al. Materials Letters[J], 2003, 57(26-27): 4187

12 Yogeswaran U, Chen S M. Sensors[J], 2008, 8(1): 290

13 Briggs E P, Walpole A R, Wilshaw P R et al. Journal of Materials Science Materials in Medicine [J], 2004, 15(9): 10219

14 Masuda H, Fukuda K. Science [J], 1995, 268(5216): 1466

15 Chahrour K M, Ahmed N M, Hashim M R et al. Journal of Physics \& Chemistry of Solids [J], 2015, 87: 1

$16 \mathrm{Hu}$ G, Zhang H, Di W et al. Applied Physics Research[J], 2009, 1(2): 531 
17 Nagaura T, Takeuchi F, Inoue S. Electrochimica Acta[J], 2008, 53(5): 2109

18 Farnan I, Dupree R, Jeong Y et al. Thin Solid Films[J], 1989, 173(2): 209

19 Coz F L, Arurault L, Datas L. Materials Characterization[J], 2010, 61(3): 283
20 Wada K, Shimohira T, Yamada M et al. Journal of Materials Science [J], 1986, 21(11): 3810

21 Zhang C, Lu Y, Ni Y et al. Nano Letters[J], 2015, 15(2): 3810

22 Shan D, Huang L, Li X et al. Journal of Physical Chemistry $C[\mathrm{~J}], 2014,118(41): 23930$

\title{
基于多层结构理论的三维纳米多孔阳极氧化铝实时扩孔机理研究
}

\author{
巴汉卿 ${ }^{1}$, 王凯歌 ${ }^{1}$, 焦 阳 $^{1}$, 金爱子 ${ }^{2}$, 白晋涛 ${ }^{1}$, 顾长志 ${ }^{2}$
}

(1. 西北大学 光电技术与功能材料国家重点实验室培育基地,

陕西省光电技术实验室，国家级光电技术与纳米功能材料及应用国际科技合作基地，陕西 西安 710069)

(2. 中国科学院物理研究所, 北京 100190)

摘 要: 多孔阳极氧化铝(PAA)的孔径大小及其均匀性可通过扩孔进行改善。以 $3 \%$ (质量分数)磷酸作为刻蚀液, 在实现 PAA 孔径扩大 的同时, 详细研究了三维状况下孔径形态的实时演变过程。发现 PAA 孔加宽在表面和截面 2 个方向上同时进行。在表面扩孔中, 磷酸 逐层蚀刻 PAA 内壁多层结构, 随着扩孔时间的增加, 扩孔速率不同。在截面扩孔中, 当扩孔时间达到某一定值时, 由于扩孔速率不同, PAA 顶部的扩孔过程较底部相对较早完成, 随后顶部扩孔速率逐渐降低, 底部扩孔速率逐渐增加。当扩孔完成时, 形成均一性良好的 理想圆形小孔。同时发现，过度增加扩孔时间，PAA 基元结构将被破坏，并由于高纵横比形成纳米线，随后被刻蚀溶液腐蚀。结合多 层结构理论详细阐明了三维 PAA 的实时扩孔机制。

关键词: 多孔阳极氧化铝; 扩孔机理; 多层结构; 截面

作者简介: 巴汉卿, 男, 1992 年生, 硕士, 西北大学光子学与光子技术研究所, 陕西 西安 710069, 电话: 029-88303687, E-mail: bahanqing@126.com 